\title{
Value of washings and brushings at fibreoptic bronchoscopy in the diagnosis of lung cancer
}

\author{
V H F Mak, I D A Johnston, M R Hetzel, Chandra Grubb
}

\begin{abstract}
A retrospective study was performed to evaluate the diagnostic yield for lung cancer from histological biopsy specimens and from washings and brushings for cytological examination taken at fibreoptic bronchoscopy. The records of 680 bronchoscopies were analysed. Of 300 patients eventually diagnosed as having a malignant lesion, 188 had had biopsy, washing, and brushing. Of these, 125 had endoscopically visible tumour (group A) and 63 had no abnormal findings or abnormal findings that were not diagnostic of malignancy (group B). In group A biopsy specimens gave a positive result in $76 \%$ of cases, washings in $49.6 \%$, and brushings in $52 \%$; biopsy material gave the only positive result in $22.4 \%$ of cases, washings in $2 \cdot 2 \%$, and brushings in $4 \cdot 8 \%$. In group $B$ biopsy specimens were positive in $36.5 \%$, washings in $38.1 \%$, and brushings in $28.6 \%$; biopsy gave the only positive result in $11 \cdot 1 \%$ of cases, washing in $9.5 \%$, and brushing in $3.2 \%$. Washing had a higher diagnostic yield than brushing in group B. Biopsy and cytological examination of either washings or brushings were found to give over $95 \%$ of all positive results in group $A$, but in group $B$ the combination of biopsy and washing was more often successful $(94.3 \%)$ than biopsy and brushing $(82.8 \%)$. It is concluded that for the maximum diagnostic yield in the diagnosis of lung cancer biopsy should be combined with cytology using both washings and brushings.
\end{abstract}

The question of which combination of cytological and histological procedures gives the best diagnostic yield from fibreoptic bronchoscopy has not been considered for many years. Previous studies have given different results ${ }^{1-8}$; reasons for this include use of different techniques for the retrieval and processing of cytological specimens, variations in the use or non-use of biplanar fluoroscopy, different numbers of biopsy specimens and different practices with regard to suspicious cytological appearances, which some but not all workers take as positive results in the analysis.

We have studied the diagnostic yield in a busy respiratory unit without access to biplanar fluoroscopy. Our aim was to determine whether a particular combination of cyto- logical and histological procedures is more effective than a single technique and, if so, which combination is best.

\section{Methods}

All diagnostic bronchoscopies, a total of 680 , performed in the respiratory unit of the Whittington Hospital from January 1982 to February 1985, were reviewed retrospectively. All were performed by one of four experienced operators. The bronchoscopy reports were assessed and the relevant cytology, histology, and microbiology reports were retrieved from the patient's notes or from the relevant laboratory archives. The records of all patients were followed for at least one year after the study to determine the subsequent clinical, surgical, or postmortem outcome. Any patient with an inadequate follow up (because of lost records, for example) or with insufficient data was excluded from the study.

The two most common reasons for bronchoscopy were an abnormal chest radiograph (493 cases) and haemoptysis (104 cases). Other reasons for bronchoscopy included dyspnoea, stridor, chronic cough, and hypercalcaemia of unknown cause.

Because this was a restrospective study, all combinations of cytological and histological procedures were found to have been used. In most cases, however, washings, brushings, and biopsy specimens were taken, especially when a tumour was visible. The sequence when all three procedures were performed was always washing, biopsy, and then brushing immediately before extraction of the bronchoscope. Washings were obtained by lavage with $20-40 \mathrm{ml}$ of normal saline and aspiration into a trap. No set number of biopsy specimens was taken.

When no lesion was seen endoscopically, "blind" cytology was performed by lavaging as described and brushing the appropriate segment as determined by the posteroanterior and lateral chest radiographs. Occasionally "blind" biopsy was also performed, the biopsy forceps being directed into the appropriate segment.

Brushings were smeared on to two to four slides and immediately fixed in 95\% alcohol. Washings were taken to the cytology laboratory and centrifuged at $1500 \mathrm{rev} / \mathrm{min}$ for five minutes, the supernatant was poured off, and the sediment of material was pipetted on to several slides and fixed with $95 \%$ alcohol. Cytological specimens were stained routinely by the Papanicolaou technique. Specimens were interpreted by the cytopathologist with- 
Figure 1 Breakdown of 680 cases studied by bronchoscopy. * Biopsy specimens, brushings, and washings taken.

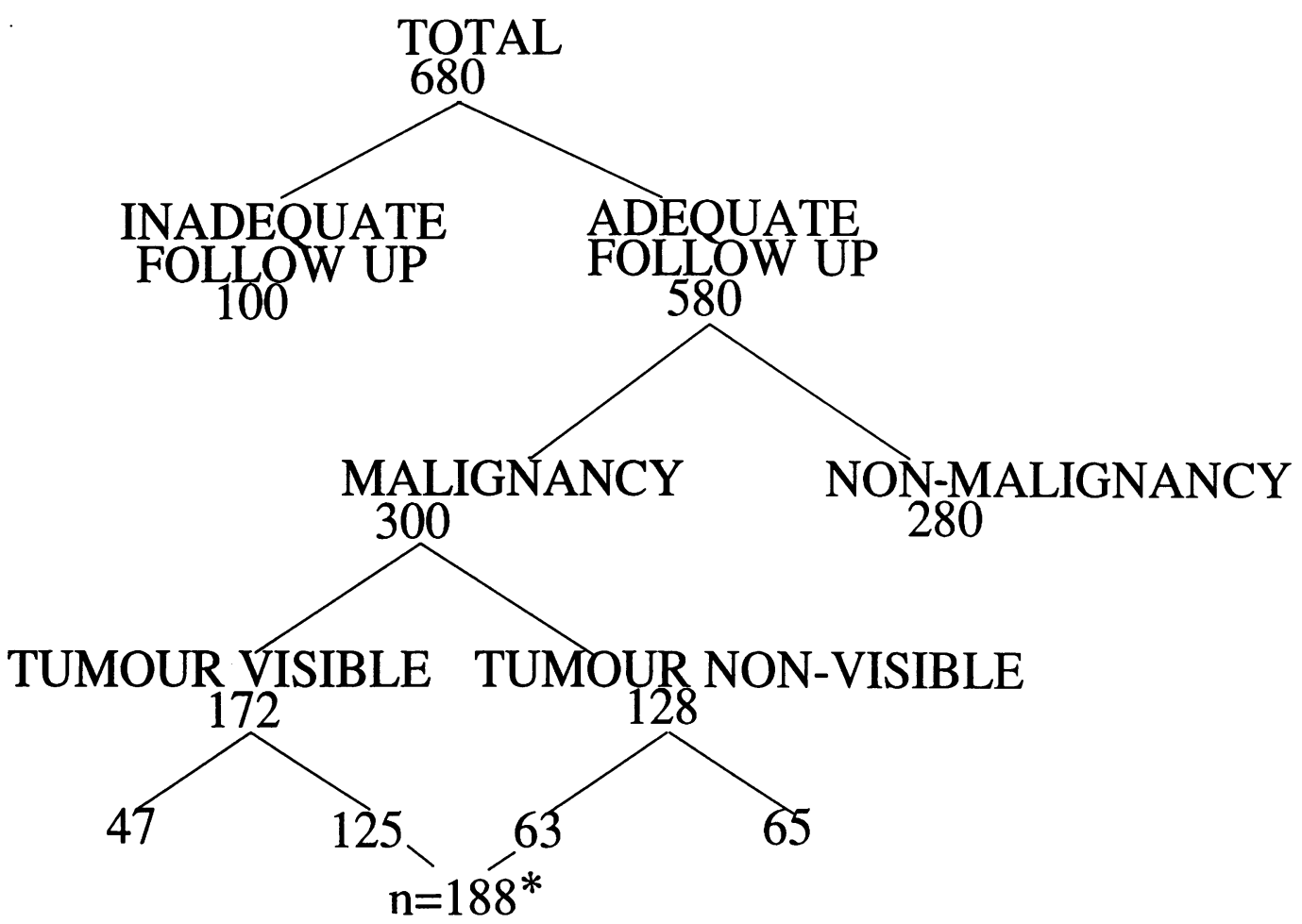

out prior knowledge of the histological result. Histological specimens were stained with haematoxylin and eosin. Only cytological reports that were diagnostic of malignancy were taken as positive results, "suspicious" cytological specimens being taken as negative.

\section{Results}

During the three years, 680 bronchoscopies were performed. Of the 680 patients, 300 were eventually diagnosed as having a malignant lesion. Of these lesions, 195 were diagnosed by histology or cytology at bronchoscopy, 22 by subsequent investigation (for example, needle aspiration biopsy), 29 after a surgical procedure (for example, open lung biopsy or mediastinoscopy), and six at necropsy. The remaining 48 patients were seen to have had a clinical course

Figure 2 Percentage of positive results from each diagnostic technique when tumour was visible (group A).

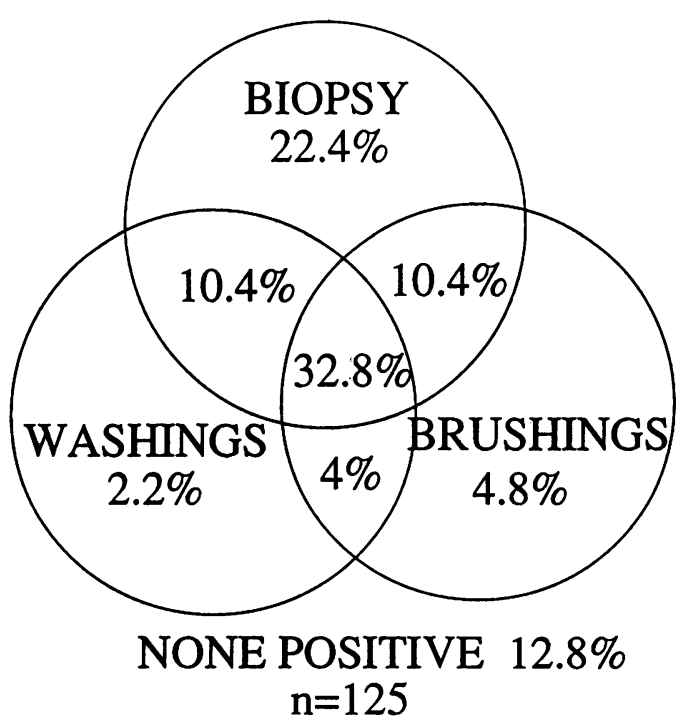

compatible with malignancy one year after their bronchoscopy. Two hundred and eighty patients either had other diseases, usually infection (especially tuberculosis) or sarcoidosis, or had no abnormality found.

Of the 300 patients with malignant disease, 188 had all three diagnostic procedures performed-that is, washing, brushing, and biopsy. Thirty seven had washing and brushing only, and 58 had a biopsy performed with either cytological procedure or had a single procedure. No diagnostic specimen was taken from 17 patients (fig 1 ).

Because we were interested in the most effective combination of procedures, we have further ainalysed the findings only from the 188 patients who had all three procedures performed. Of these, 125 had endoscopically visible tumour (group A) and 63 had either normal or equivocal bronchoscopic appearances (group B). The percentage of positive results obtained in each group with each technique is shown in figures 2 and 3 . In group A, even though the lesions were visible, washings gave the only positive result in $2.2 \%(3 / 125)$ and brushings in $4.8 \%$ (6/125); cytology alone provided the diagnosis in $11 \%(14 / 125)$. In group B washings gave the only positive result in $9.5 \%(6 / 63)$ and brushings in $3.2 \%(2 / 63)$; cytology alone provided the diagnosis in $19 \%(12 / 63)$. Washings produced more positive diagnoses than brushings in group $B(p<0.001$, two sided Fisher's exact test).

There were no false positive cytological results so far as we can tell, but the cell type occasionally differed from that given in the histological report or from the final "tissue" diagnosis made after operation or necropsy. The cell type based on washings matched the cell type in the histological report in $76 \%$ of the cases in which both washings and histological 
Figure 3 Percentage of positive results from each diagnostic technique when no tumour was visible (group $B$ ).

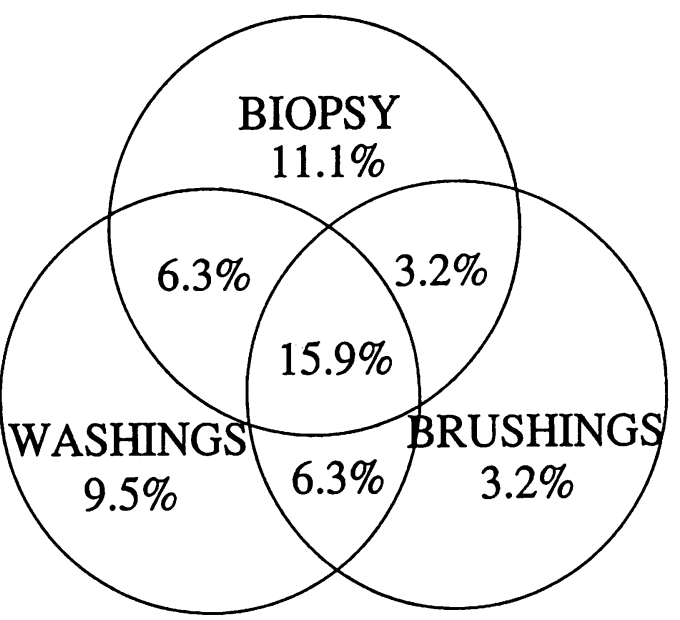

NONE POSITIVE $44.4 \%$ $\mathrm{n}=63$

specimens were positive, and the cell type of the brushings matched that given in the histological report in $72^{\circ}{ }_{0}$ of cases.

Cytology was of varying sensitivity for identifying the tumour type in the 96 cases where cytological and histological results could be compared. Cytological matched histological diagnosis in $43 / 54$ cases of squamous cell carcinomas, 20/22 of small cell carcinomas, 3/7 of large cell carcinomas, and 7/13 of adenocarcinomas.

\section{Discussion}

Fibreoptic bronchoscopy has been in regular use for many years for investigating patients with suspected lung cancer. Nevertheless, no definitive conclusion has been reached on the most effective combination of perbronchoscopic diagnostic techniques. In particular, the relative value of the cytology of bronchial brushings and of washings has been unclear,

Summary of studies comparing success rates of cytological and histological techniques in bronchoscopy for the diagnosis of lung cancer

\begin{tabular}{|c|c|c|c|c|c|}
\hline \multirow[b]{2}{*}{ First author } & \multicolumn{2}{|c|}{ NQ of patients } & \multirow[b]{2}{*}{ Technique $†$} & \multicolumn{2}{|c|}{ Success rate $(\%)$} \\
\hline & Total & $\begin{array}{l}\text { With } \\
\text { malignancy }\end{array}$ & & Group $A$ & Group B \\
\hline $\begin{array}{l}\text { Zavala }^{1} \\
\text { Richardson }^{2} \\
\text { Solomon }^{3}\end{array}$ & $\begin{array}{r}72 \\
200 \\
103\end{array}$ & $\begin{array}{r}52 \\
130 \\
47\end{array}$ & $\begin{array}{l}\mathrm{Br} \\
\mathrm{Br} \\
\mathrm{Br} \\
\mathbf{W}\end{array}$ & $\begin{array}{r}94 \\
92 \\
91 \\
9\end{array}$ & $\begin{array}{l}78 \\
78 \\
83 \\
22\end{array}$ \\
\hline Zavala $^{4}$ & 600 & 330 & $\begin{array}{l}\mathrm{w} \\
\mathrm{Br} \\
\mathrm{Bi}\end{array}$ & $\begin{array}{l}93 \\
93 \\
97\end{array}$ & $\begin{array}{l}22 \\
76 \\
70\end{array}$ \\
\hline Kvale $^{5}$ & 228 & 95 & $\begin{array}{l}\mathbf{B r} \\
\mathbf{B r} \\
\mathbf{B i} \\
\text { All }\end{array}$ & $\begin{array}{l}77 \\
63 \\
71 \\
86\end{array}$ & $\begin{array}{l}26 \\
20 \\
37 \cdot 5 \\
46 \cdot 6\end{array}$ \\
\hline Stringfield ${ }^{6}$ & 360 & 107 & $\begin{array}{l}\text { Br } \\
\text { W } \\
\text { Bi } \\
\text { All }\end{array}$ & $\begin{array}{l}52 \cdot 6 \\
61 \cdot 5 \\
68 \\
85\end{array}$ & $\begin{array}{l}31 \\
24 \\
27 \cdot 6 \\
48\end{array}$ \\
\hline Chaudhary $^{7}$ & 114 & 114 & $\begin{array}{l}\mathrm{An} \\
\mathbf{B r} \\
\mathbf{W} \\
\mathrm{Bi} \\
\text { All }\end{array}$ & $\begin{array}{l}49 \cdot 1 \\
75 \cdot 4 \\
65 \cdot 8 \\
95 \cdot 8\end{array}$ & $\begin{array}{l}= \\
=\end{array}$ \\
\hline $\operatorname{Lam}^{8}$ & 1405 & 484 & $\begin{array}{l}\mathrm{Min}_{+} \\
\mathrm{Br} \\
\mathbf{W} \\
\mathrm{Bi} \\
\mathrm{All}\end{array}$ & $\begin{array}{l}74 \\
76 \\
82 \\
94\end{array}$ & $\begin{array}{l}\overline{52} \\
52 \\
61 \\
86\end{array}$ \\
\hline Present study & 680 & $188^{\star}$ & $\begin{array}{l}\mathrm{Br} \\
\mathbf{W} \\
\mathrm{Bi} \\
\text { All }\end{array}$ & $\begin{array}{l}52 \\
49 \cdot 6 \\
76 \\
87 \cdot 2\end{array}$ & $\begin{array}{l}28 \cdot 6 \\
38 \cdot 1 \\
36 \cdot 5 \\
55 \cdot 6\end{array}$ \\
\hline
\end{tabular}

*Only those who had all three procedures included.

$+\mathrm{Br}$ - brushing; $\mathrm{W}$ - washing; $\mathrm{Bi}$-biopsy; All-all three techniques taken together.

†Includes sputum samples taken before and after bronchoscopy. and in many units the most common combination of procedures is cytological brushing and biopsy.

Several previous studies have examined this problem (summarised in the table). In most of these studies washings offered no advantage over brushings, though Stringfield et al, ${ }^{6}$ Chaudhury et al, ${ }^{7}$ and Lam et al did find that washings conferred an additional yield. Only a few of these studies, however, used all three techniques-that is, biopsy, brushing, and washing. ${ }^{5-8}$ All the studies used biplanar or uniplanar fluoroscopy during bronchoscopy for peripheral lesions, but this is not routinely available in many respiratory units in Britain. In several studies "suspicious" cytological specimens may have been included in the positive group; this was certainly the case for Zavala et al. ${ }^{1}$

The number of cases that a particular combination of procedures would pick up can be calculated. In group $\mathrm{A}$, if washing and biopsy together are considered, the combination would have picked up $94.5^{\circ}$ of all positive cases; brushing and biopsy would have picked up $97 \cdot 2^{\circ}$, and washing and brushing together only $74 \cdot 3^{\circ}$. In group B washing and biopsy together would have picked up $94.3 \%$ of all positive cases, brushing and biopsy $82.8 \%$, and washing and brushing $80^{\circ}$. Even in cases in which obvious tumour was visible cytology alone provided the diagnosis in $11^{\circ}{ }_{0}$. The main finding of the present group therefore is that the maximum diagnostic yield is obtained by combining biopsy with both the cytological procedures of brushing and washing. The additional benefit of performing both cytological procedures as well as biopsy is small, though substantially more for peripheral lesions, with washing significantly better than brushing. Bronchoscopy may be unpleasant for patients, however, and so maximising the diagnostic yield is important. The additional cost in terms of the bronchoscopist's time and materials is negligible and the main cost is that of the additional work for the cytologist. This could be reduced if the cytologist received both washings and brushings but held one type in reserve-either brushings or washings, depending on his bias or experience-and examined these specimens only if the others proved non-contributory.

Certain problems with this study need to be explored. The study was retrospective and we were unable to establish the final outcome for some of those who had had bronchoscopy. We have no particular reason to believe that the outcome in the missing cases was substantially different from that in the others and therefore consider that a major bias from this source is unlikely. There were undoubtedly variations in the techniques of the bronchoscopists, as there would be in any respiratory unit. This would not have introduced systematic bias but, for example, no standard number of biopsy specimens was taken. Gellert et al $^{9}$ showed that at least five biopsy specimens were required to give more than a $90 \%$ probability of obtaining a positive specimen and Popovitch et al ${ }^{10}$ found that the maximum yield, at least for visible 
tumours, was reached after the fourth specimen. If a more consistent number of biopsy specimens had been taken in our study, the yield from biopsy may have been greater and the additional yield from cytology correspondingly less.

When we undertook this study we were unaware of the findings of Lam et al. ${ }^{8}$ It is reassuring that we have produced similar results and have come to the conclusion they reached in their larger study, in which most patients had biopsy and both cytological procedures. Their study, however, was performed with the aid of uniplanar fluoroscopy for non-endoscopically visible lesions, and patients who had bronchoscopy but may not have had a cytological or histological diagnosis made were not included.

A definitive answer to the question of which combination of cytological and histological procedures gives the highest diagnostic yield requires a prospective study of brushing and biopsy versus brushing, washing and biopsy. Until such data become available, however, our study suggests that biopsies and both brush- ings and washings should be carried out in the investigation of suspected lung cancer.

1 Zavala DC, Richardson RH, Mukeriee PK, Rossi NP, Bedell $\mathrm{GN}$. Use of the bronchofibrescope for bronchial brush GN. Use of the bronchofibresc

2 Richardson RH, Zavala DC, Mukeriee PK, Bedell GN. The use of fibreoptic bronchoscopy and brush biopsy in the diagnosis of suspected pulmonary malignancy. Am Rev Respir Dis 1974;109:63-6.

3 Solomon DA, Solliday NH, Gracey DR. Cytology in fibreoptic bronchoscopy. Chest 1974;65:616-9.

4 Zavala DC. Diagnostic fibreoptic bronchoscopy: techniques and results of biopsy in 600 patients. Chest 1976;68:12-9.

5 Kvale PA, Bode FR, Kini S. Diagnostic accuracy in lung cancer. Chest 1976;69:752-7.

6 Stringfield JT, Markowitz DJ, Bentz RR, Welch MH, Weg JG. The effect of tumour size and location on diagnosis in JG. The effect of tumour size and location on diagn

7 Chaudhary BA, Yoneda K, Burki NK. Fibreoptic bronchoscopy: comparison of procedures used in the diagnosis of lung cancer. J Thorac Cardiovasc Surg 1978;76:33-7.

8 Lam WK, So SY, Hsu C, Yu DYC. Fibreoptic bronchoscopy in the diagnosis of bronchial cancer: comparison of washings, brushings and biopsies in central and peripheral tumours. Clin Oncol 1983;9:35-42.

9 Gellert AR, Rudd RM, Sinha G, Geddes DM. Fibreoptic bronchoscopy: effect of multiple biopsies on diagnostic yield in bronchial carcinoma. Thorax 1982;37:684-7.

10 Popovich JR, Kvale PA, Eichenhorn MS, Radke JR, Chorodnik N, Fine G. Diagnostic accuracy of multiple biopsies from flexible fibreoptic bronchoscopy. Am Rev Respir Dis 1982;125:521-3. 